\title{
The WHO-ERS Smoking Cessation Training Project: the first year of experience
}

\author{
Dongbo Fu ${ }^{1}$, Christina Gratziou ${ }^{2,3}$, Carlos Jiménez-Ruiz ${ }^{4}$, Marine Faure ${ }^{5}$, \\ Brian Ward ${ }^{5}$, Sofia Ravara ${ }^{6,7}$, Vinayak Mohan Prasad ${ }^{1}$, Kristina Mauer-Stender $^{8}$, \\ Jagdish Kaur ${ }^{9}$, Angela Ciobanu ${ }^{10}$, Syed Mahfuzul Huq ${ }^{11}$ and \\ Paraskevi Katsaounou (1) ${ }^{12}$
}

\begin{abstract}
${ }^{1}$ Tobacco Free Initiative, Prevention of Noncommunicable Diseases, World Health Organization, Geneva, Switzerland. ${ }^{2}$ Smoking Cessation Centre, Evgenidio Hospital, Athens, Greece. ${ }^{3}$ National and Kapodistrian University of Athens, Athens, Greece. ${ }^{4}$ Health, Public Health Institute, Madrid, Spain. ${ }^{5}$ Advocacy and EU Affairs, European Respiratory Society, Brussels, Belgium. ${ }^{6}$ Faculty of Health Sciences, University of Beira Interior, Covilha, Portugal. ${ }^{7}$ Public Health Research Centre (CISP), ENSP, NOVA University, Lisbon, Portugal. ${ }^{8}$ World Health Organization Regional Office for Europe, Copenhagen, Denmark. ${ }^{9}$ World Health Organization Regional Office for South-East Asia, New Delhi, India. ${ }^{10}$ WHO Country Office, Republic of Moldova, Chisinau, Moldova. ${ }^{11}$ WHO Country Office for Bangladesh, Dhaka, Bangladesh. ${ }^{12}$ First ICU Evaggelismos Hospital, Faculty of Medicine, National and Kapodistrian University of Athens, Athens, Greece.
\end{abstract}

Correspondence: Paraskevi Katsaounou, Faculty of Medicine, National and Kapodistrian University of Athens, Athens 11527, Greece. E-mail: paraskevikatsaounoudgmail.com

\section{@ERSpublications}

Strategic @ERSTalk-@WHO alliance to address tobacco use by training health professionals on brief advice resulted in establishing smoking cessation in real care settings with quit rates higher than the literature and high propensity for wider dissemination http://ow.ly/lWDF30krq5V

Cite this article as: Fu D, Gratziou C, Jiménez-Ruiz C, et al. The WHO-ERS Smoking Cessation Training Project: the first year of experience. ERJ Open Res 2018; 4: 00070-2018 [https://doi.org/ $10.1183 / 23120541.00070-2018]$.

Globally, $>7$ million people die each year from tobacco use [1]. If no urgent action is taken, $\geqslant 100$ million people will die from tobacco in the next 15 years [2]. Between 2010 and 2025, if tobacco use has a 50\% relative reduction, it will help almost reach the global target to reduce premature noncommunicable disease (NCD) mortality by $25 \%$ by 2025 [3]. The World Health Organization (WHO) Framework Convention on Tobacco Control (FCTC) Article 14 emphasises supporting current tobacco users to quit as a key component of comprehensive tobacco control strategy to avert premature NCD deaths $[4,5]$.

As the leading medical organisation in respiratory medicine, the European Respiratory Society (ERS) works strategically in tobacco control and strongly supports tobacco cessation, both from a policy and clinical perspective [6]. ERS created SmokeHaz [7], a website on systematic reviews of the effects of active and passive smoking on respiratory health, to provide education and disseminate the best tobacco cessation standards $[8,9]$. Moreover, ERS is very active in tobacco control advocacy, led by the ERS Tobacco Control Committee, and demands a total ban on any relationship with the tobacco industry.

Implementing tobacco cessation along with tobacco control measures will have synergistic effect and maximise their impact at a population level [4]. The updated Appendix 3 of the WHO Global Action Plan for Prevention and Control of NCDs 2013-2020, endorsed in May 2017 by the 70th World Health Assembly, recommends three population-wide tobacco cessation approaches (brief advice in health systems, national toll-free quit lines and mobile text messaging (mCessation)) as cost-effective NCD interventions to achieve the global NCD targets [10]. Tobacco screening and brief interventions are
Received: May 222018 | Accepted: May 272018

Copyright $\odot$ ERS 2018. This article is open access and distributed under the terms of the Creative Commons Attribution Non-Commercial Licence 4.0. 
among the three highest-ranking clinical preventive services [11, 12]. Hence, WHO recommends establishing a comprehensive tobacco cessation and treatment system consisting of brief advice, a national toll-free quit line and mCessation, as part of any comprehensive tobacco control programme [10]. Brief advice from healthcare professionals is one of the first actions towards establishing a comprehensive tobacco cessation and treatment system in any country [4]. Training has a key role to play in promoting the delivery of all the aforementioned interventions as part of a health system strengthening approach.

The WHO report on the global tobacco epidemic in 2017 [13] reveals that currently, only 35 countries provide cessation support in most of their primary care facilities and only 29 countries have cessation support in most of their hospitals. 70 countries are not providing cessation support in any of their primary care facilities and 77 countries are not providing cessation support in any of their hospitals. This situation is quite dismal. Basic training for tobacco cessation is nonexistent or poorly implemented in most countries. The incorporation of evidence-based smoking cessation into standard medical practice started in the last few decades and only few facilities have since incorporated it globally. The Global Health Professions Student Survey in 31 countries revealed that $<40 \%$ of third-year students had received formal training in tobacco cessation counselling $[14,15]$. Reports show that physicians do not routinely provide evidence-based tobacco cessation treatment to their patients, mainly due to lack of experience with smoking cessation techniques [16]. Inadequacy of health professionals' training in tobacco cessation is a critical health system weakness resulting in inconsistent delivery of tobacco cessation brief advice by healthcare providers as well as low availability of tobacco cessation services in many countries.

\section{WHO-ERS collaboration on smoking cessation training}

ERS already collaborates with the WHO for the full implementation of the WHO FCTC at the European, national and regional levels. Recognising the importance of tobacco cessation to attain the global NCD targets and the need for training health professionals in tobacco cessation in target countries, WHO and ERS, in 2016, formed a novel collaboration: a successive 3-year project (2016-2019) to support WHO's training activities for building capacity of WHO Member States to provide tobacco cessation interventions to all patients with respiratory diseases both in hospital and primary care settings. Three countries with high prevalence of tobacco use and low availability of tobacco cessation support were selected as target countries to implement the Year 1 project (Greece, Republic of Moldova and Bangladesh).

\section{Year 1 project objectives, activities and achievements}

WHO and ERS have successfully implemented the joint project, and achieved the two designated objectives of Year 1 between June 2016 and March 2017: 1) a national training network capable of providing further training on brief tobacco interventions for health professionals was established in each of the three target countries (figure 1); and 2) an online training course on brief tobacco interventions for health professionals was developed based on the WHO training package.

Three Train the Trainer workshops were jointly conducted by WHO and ERS experts (figure 1). 30 future trainers were trained on brief tobacco intervention in each country and subsequently qualified to train primary care providers on brief tobacco interventions.

Consequently, the existing training centres for on-the-job training of primary care providers were strengthened in each of the three countries to train primary care providers on brief tobacco interventions. The national training teams conducted four to six training workshops for primary care providers from two to four cities or districts in each country. All trained primary care providers were supported to deliver the "5As" and "5Rs" brief tobacco interventions from February to June 2017. >10000 tobacco users with respiratory disease were identified and given brief advice on quitting (table 1). It is worth emphasising that the quit rates were higher than those in other studies [17].

Moreover, a six-module online training course, "Training for primary care providers: brief tobacco interventions" (English version), has been developed to equip primary care providers with the knowledge and appropriate skills for delivering brief tobacco interventions based on the part 3 of WHO training package "Strengthening health systems for treating tobacco dependence in primary care" [18], using the Storyline software (Articulate, New York, NY, USA). The online course is accessible at http://tobaccocessation-elearning.hk/story_html5.html.

This project gained great visibility worldwide by adding the logos of ERS, WHO and concerned national authorities to all workshop materials, press/news releases issued by national authorities [19], WHO headquarters, regional and country offices [20,21], and dissemination of the project results at several international conferences including the seventh European Conference on Tobacco or Health in 2017, the European Network for Smoking and Tobacco Prevention conference in 2017 and World Conference on Tobacco or Health in 2018. 

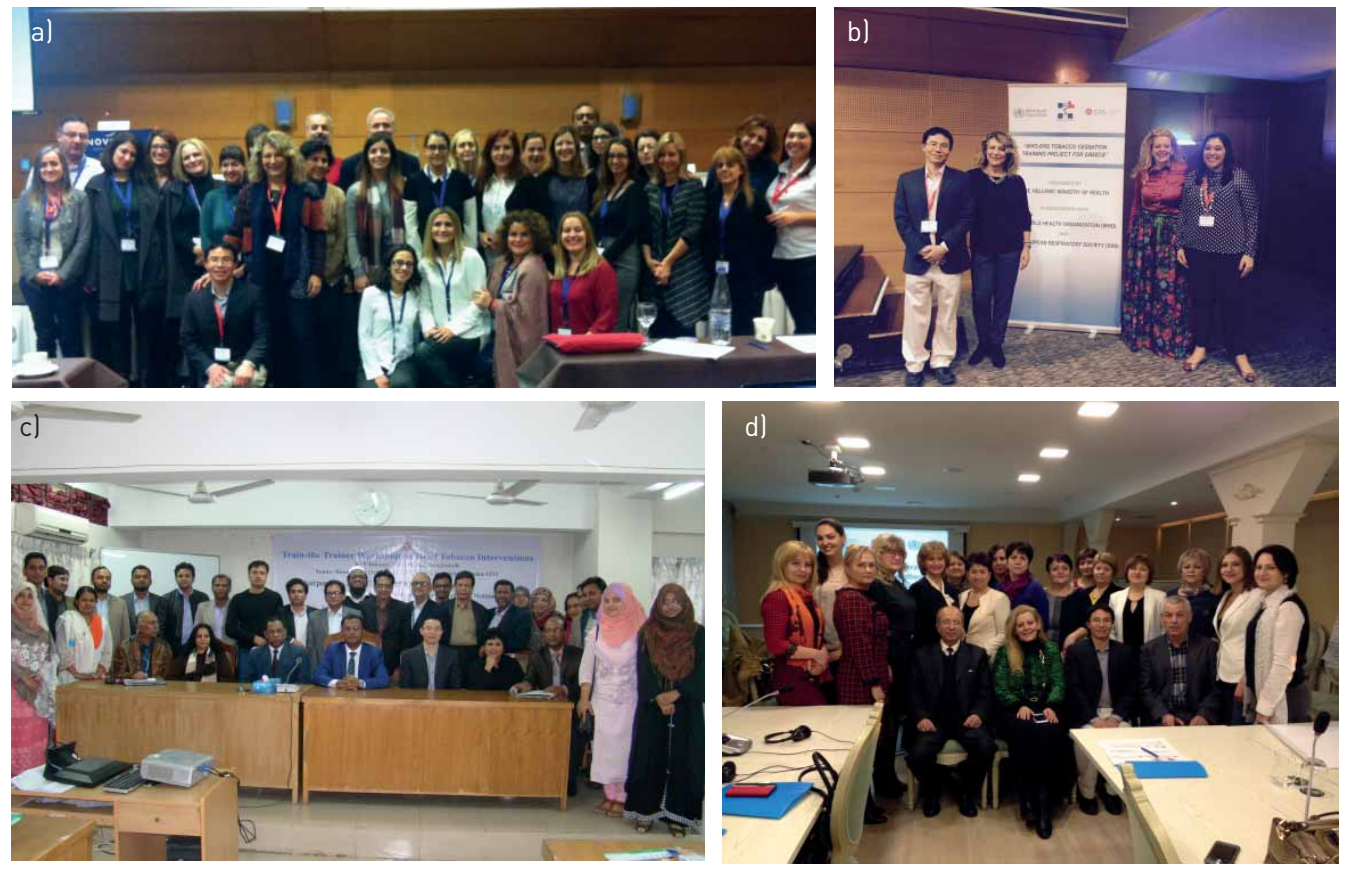

FIGURE 1 World Health Organization-European Respiratory Society Train the Trainer project first year experience in a, b) Greece (2016), c) Bangladesh (2017) and d) the Republic of Moldova (2016).

\section{Discussion}

The WHO-ERS Smoking Cessation Training Project is a concrete example of how international cooperation is essential for building capacity of WHO Member States' health systems to promote one of the wide-reach approaches to tobacco cessation: brief tobacco interventions as part of healthcare providers' routine practice. The project and its contribution were highly appreciated by all three participating

TABLE 1 The project activities and achievements in three countries in 2016-2017

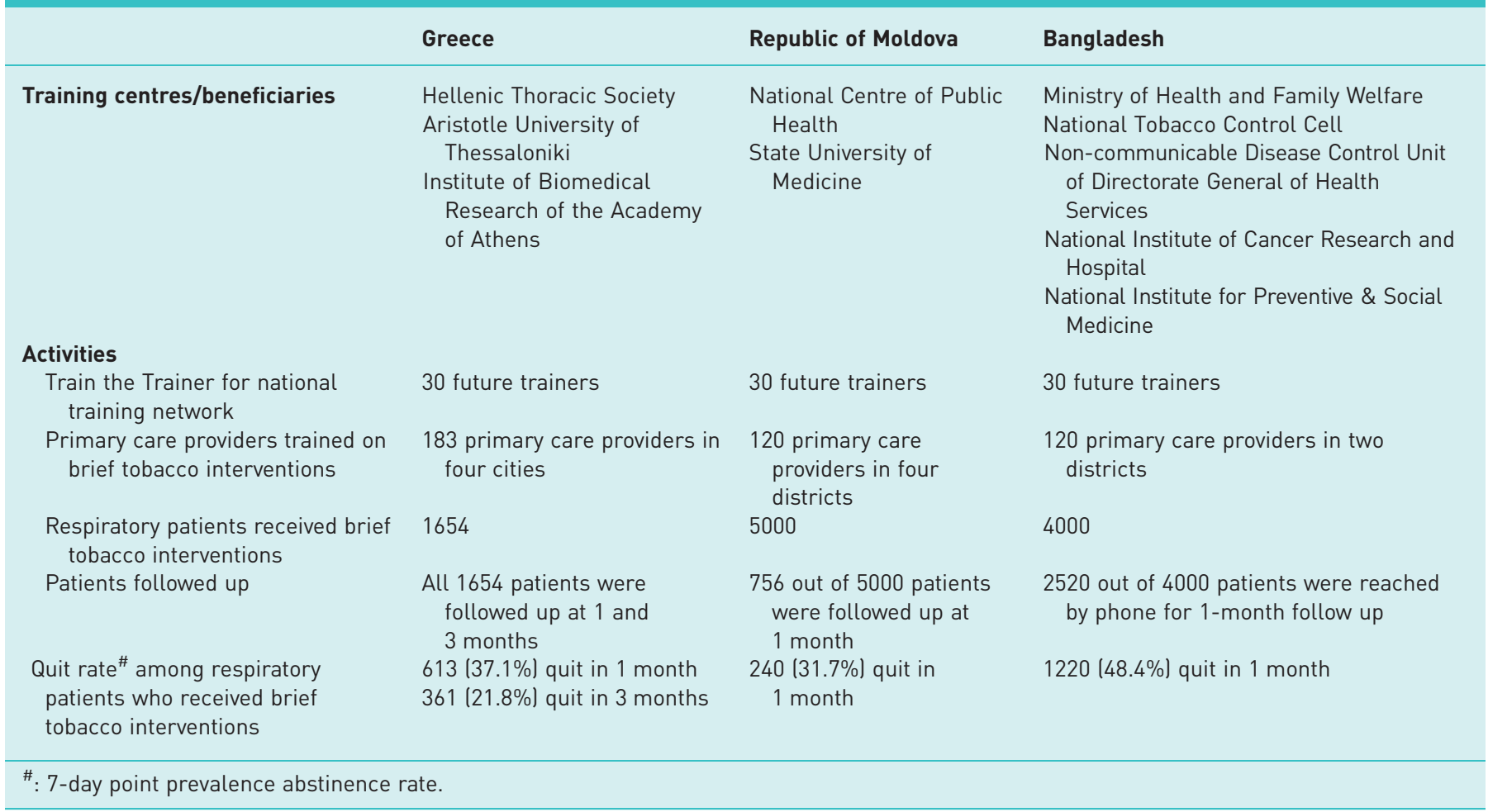


countries because it met their critical and urgent needs to strengthen their health systems to improve access to tobacco cessation services as part of their NCD prevention and control efforts.

The Year 1 project results prove that this collaboration could foster sustainable infrastructure elements to promote tobacco cessation and lead to a significant impact on reducing tobacco use in the target countries. As a result of the project, a robust training network with 30 qualified trainers is available in each country. The project helped train $>400$ health professionals who provided brief tobacco interventions to 10000 respiratory patients with a 1 -month quit rate of $>30 \%$ and 3 -month rate of $>20 \%$ in the three target countries. All three countries have planned follow up actions to further strengthen their national training networks and to expand training for health professionals on tobacco cessation. Greece planned to further strengthen the National Training Network in brief tobacco interventions to enhance people's access to smoking cessation interventions as part of everyday community health services; Moldova planned to expand the tobacco cessation training for primary care providers to more districts as part of WHO Package of Essential Non-communicable Disease Interventions for Primary Health Care [22] implementation; and Bangladesh planned to strengthen the tobacco cessation training network and to expand tobacco cessation service as a component of Essential Service Package in Primary Care.

Despite the fact all countries had expressed strong interest and commitment to the project, the project activities under Objective 1 were implemented with a slight delay due to very tight schedules and some unavoidable events. This also undermined a longer follow-up, in order to assess 6-month tobacco cessation outcomes.

The successful collaboration between WHO, ERS and other experts created a synergistic effect that is expected to spill over to neighbouring countries. The positive project results have stimulated many tobacco cessation training requests from other WHO Member States, leading to increased demand, which calls for WHO and ERS to continue and extend this project.

Disclaimer: For the authors who are staff members of the World Health Organization (WHO), the authors alone are responsible for the views expressed in this article and they do not necessarily represent the decisions, policy or views of the WHO.

Conflict of interest: D. Fu reports receiving grants from the European Respiratory Society. M. Faure is an employee of the European Respiratory Society. B. Ward is an employee of the European Respiratory Society. P. Katsaounou reports receiving honoraria from Pfizer, BI, GSK, Menarini and Chiesi, outside the submitted work. S.M. Huq reports receiving grants from the European Respiratory Society. V.M. Prasad reports receiving grants from the European Respiratory Society.

Support statement: Funding was received from the European Respiratory Society (WHO projects - 16037). Funding information for this article has been deposited with the Crossref Funder Registry.

\section{References}

1 GBD 2016 Risk Factors Collaborators. Global, regional, and national comparative risk assessment of 84 behavioural, environmental and occupational, and metabolic risks or clusters of risks, 1990-2016: a systematic analysis for the Global Burden of Disease Study 2016. Lancet 2017; 390: 1345-1422.

2 World Health Organization. WHO global report: mortality attributable to tobacco. Geneva, World Health Organization, 2012.

3 Kontis V, Mathers CD, Rehm J, et al. Contribution of six risk factors to achieving the $25 \times 25$ non-communicable disease mortality reduction target: a modelling study. Lancet 2014; 384: 427-437.

4 World Health Organization. Guidelines for implementation of Article 14 of the WHO FCTC. Geneva, World Health Organization, 2010.

5 World Health Organization. WHO Global Action Plan for the Prevention and Control of Noncommunicable Diseases, 2013-2020. Geneva, World Health Organization, 2013.

6 Gibson JG, Loddenkemper R, Sibille Y, et al., eds. The European Lung White Book. 2nd Edn. Sheffield, European Respiratory Society, 2013.

7 European Lung Foundation. SmokeHaz. www.europeanlung.org/en/projects-and-research/projects/smokehaz/home

8 Tønnesen P, Carrozzi L, Fagerström KO, et al. Smoking cessation in patients with respiratory diseases: a high priority, integral component of therapy. Eur Respir J 2007; 29: 390-417.

9 Jiménez-Ruiz CA, Andreas S, Lewis KE, et al. Statement on smoking cessation in COPD and other pulmonary diseases and in smokers with comorbidities who find it difficult to quit. Eur Respir J 2015; 46: 61-79.

10 World Health Organization. Updated Appendix 3 of the WHO Global NCD Action Plan 2013-2020. Geneva, World Health Organization, 2017.

11 Maciosek MV, Coffield AB, Edwards NM, et al. Priorities among effective clinical preventive services: results of a systematic review and analysis. Am J Prev Med 2006; 31: 52-61.

12 VanSchayck OCP, Williams S, Barchilon V, et al. Treating tobacco dependence: guidance for primary care on life-saving interventions. Position statement of the IPCRG. NPJ Prim Care Respir Med 2017; 27: 38.

13 World Health Organization. WHO report on the global tobacco epidemic, 2017: Monitoring tobacco use and prevention policies. Geneva, World Health Organization, 2017. 
14 Warren CW, Sinha DN, Lee J, et al. Tobacco use, exposure to secondhand smoke, and cessation counseling among medical students: cross-country data from the global health professions student survey (GHPSS), 2005-2008. BMC Public Health 2011; 11: 72.

15 Yang T, Yu L, Bottorff JL, et al. Global Health Professions Student Survey (GHPSS) in tobacco control in China. Am J Health Behav 2015; 39: 732-741.

16 van Eerd EAM, BechRisør M, Spigt M, et al. Why do physicians lack engagement with smoking cessation treatment in their COPD patients? A multinational qualitative study. NPJ Prim Care Respir Med 2017; 27: 41.

17 US NCI, World Health Organization. The Economics of tobacco and Tobacco Control. National Cancer Institute Tobacco Control Monograph 21. Bethesda, US DHHS, NIH and NCI, 2016.

18 World Health Organization. WHO capacity building for tobacco control training package 4: Strengthening health systems for treating tobacco dependence in primary care. Geneva, World Health Organization, 2013.

19 Hellenic Ministry of Health. http://moh.gov.gr/articles/ministry/grafeio-typoy/press-releases/4253-programmadiakophs-kapnismatos-laquo-who-ers-ekpaideysh-ekpaideytwn

20 World Health Organization. Tobacco Free Initiative (TFI). www.who.int/tobacco/quitting/ers-collaborationcessation-training/en/

21 WHO Bangladesh. WHO supports Training of Trainers on tobacco cessation. www.searo.who.int/bangladesh/ enbantobaccocessationtot/en/

22 World Health Organization. Package of essential noncommunicable disease: interventions for primary health care in low-resource settings. Geneva, World Health Organization, 2010. 